\title{
Patients' perspectives of living with a percutaneous endoscopic gastrostomy (PEG)
}

\author{
Lena Martin ${ }^{1,2^{*}}$, John Blomberg ${ }^{1,3}$ and Pernilla Lagergren ${ }^{1}$
}

\begin{abstract}
Background: Since enteral nutrition therapy is the preferred nutritional support for dysphagic patients with a range of diagnoses, PEG has become part of traditional care. However, enteral nutrition with PEG transfers treatment responsibility and activity to the patients and their carers, so the advantages should be discussed. The aim of this study was therefore to investigate patients' experience of living with a percutaneous endoscopic gastrostomy (PEG) in order to increase the understanding of patients' need for support.
\end{abstract}

Method: In a prospective study at Karolinska University Hospital in Sweden, data were collected consecutively at the time of PEG and two months later using a study-specific questionnaire about each patient's experience of living with a PEG. Fishers exact test was used to test for statistically significant difference at five per cent level.

Results: There were 104 responders (response rate of 70\%). Women felt more limited in daily activity compared to men $(p=0.004)$. Older patients experienced a more limited ability to influence the number of feeding times compared to younger $(p=0.026)$. Highly educated patients found feeding more time-consuming $(p=0.004)$. Patients with a cancer diagnosis reported that the PEG feeding interfered with their oral feeding more than patients with a neurological disease $(p=0.009)$. Patients mostly contacted the PEG outpatient clinic with problems regarding their PEG, and were mainly assisted by their spouse rather than district nurses.

Conclusions: PEG feeding is time-consuming and interferes with daily life. Although $73 \%$ was satisfied, patients' experiences of living with a PEG may be dependent on age, sex, education and diagnosis. Spouses are the main carers for PEG patients at home, and patients prefer to go to the PEG outpatient clinic for help if problems occur.

Keywords: Experience, Impact, Nutrition, Support

\section{Background}

The growing awareness of the relevance of nutrition support in the treatment of diseases has contributed to a rapid increase in the use of percutaneous endoscopic gastrostomy (PEG) worldwide [1,2]. For patients with preserved intestinal function but with inadequate or no independent oral food intake, enteral nutrition therapy via PEG is one of the preferred alternatives to nutrition support [3]. Appropriate nutritional interventions enable a reduction of surgical complications [4], shorten the recovery time and the length of hospital stay [5], improve

\footnotetext{
* Correspondence: lena.martin@karolinska.se

${ }^{1}$ Unit of Upper Gastrointestinal Research, Department of Molecular Medicine and Surgery, Karolinska Institutet, Norra Stationsgatan 67, 2nd floor, SE-171 76 Stockholm, Sweden

${ }^{2}$ Department of Clinical Nutrition and Dietetics, Karolinska University Hospital, Stockholm, Sweden

Full list of author information is available at the end of the article
}

tolerance to treatment [6] and even increase the rate of survival [7]. PEG has become a part of traditional care for a range of diagnoses e.g., tumours of the head and neck region or the oesophagus, in the care of the elderly and patients with neurological impairment (e.g. stroke, ALS and multiple sclerosis).

The PEG is discrete and does not interfere with speech or swallowing. Since the insertion of the PEG is a minor surgical procedure there is a common belief that it is harmless and has a low impact on daily life. Having the ability to stay at home may decrease clinical costs and even improve quality of care with supporting nutrition teams [8]. However, its benefits in clinical practice are not yet established $[9,10]$. There are qualitative disadvantages of having a PEG since it moves treatment from inpatient settings to the home, with a need for care from district nurses and general practitioners, sometimes with

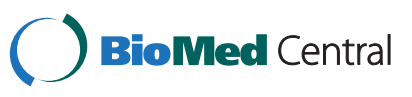


limited experience in dealing with problems regarding PEG and PEG feeding $[8,11]$. Moreover, it transfers treatment responsibility and activity to patients and their carers to a large extent. With enteral nutrition support, the social role of a meal disappears, removing all pleasure from mealtimes. This interference with social life seems to be of greater importance than PEG related problems of discomfort, leakage or blockage [12]. There is limited research exploring patients' experiences of living with a PEG and to what extent support is needed. The aim of this study, therefore, was to increase the understanding of how to support patients that are condemned to live with a PEG by investigating patients' experiences of living with a PEG.

\section{Methods}

\section{Study design and data collection}

A prospective cohort study was carried out at the Karolinska University Hospital in Stockholm, Sweden, during the period from 3 June, 2005 to 31 December, 2007. The data collection has been described in detail in a previous study [13]. In brief, all consecutive patients referred for PEG and had had their PEG for at least 2 months were eligible for inclusion in the study. Patients were excluded if they by any reason did not give their informed consent, did not understand the Swedish language, were too ill or could not communicate for other reasons. Baseline data at the time of PEG was collected prospectively through a predefined study protocol including information about patient characteristics (e.g., age, sex, marital status, education level) and clinical details (e.g., diagnosis, weight and height). At the 2-month follow-up, all patients remaining with a PEG were asked to complete a study specific questionnaire about their experience of living with a PEG. The questionnaire was tested for face validity in a number of patients and some minor changes were made. It included 16 questions of which we excluded six questions that were not consistent with our hypothesis. For the purpose of the current study we selected 10 questions assessing interference with daily activity, sleep, time-consumption, ability to influence the number of feeding occasions, feeling of confidence with self feeding, daily feeding, interference with oral intake and satisfaction. The response alternatives to all questions were 1) "not at all", 2) "a little", 3) "quite a bit" and 4) "very much".

\section{The PEG procedure}

A detailed description of the PEG procedure has been published elsewhere [13]. In brief, all patients were given oral as well as written information before the insertion of the PEG. The information included a description of the procedure, the brand name of the PEG catheter, detailed instructions of how to solve common problems associated with PEG, how to perform daily care of the wound site and the catheter, general nutrition advice and telephone numbers of the PEG outpatient clinic and of the dietician for contact whenever advice about the PEG device or nutrition would be needed. The PEGs were inserted by experienced surgeons assisted by experienced endoscopists.

\section{The PEG outpatient clinic}

The care pathway for the PEG patients at Karolinska University Hospital is multidisciplinary and led by specially trained nurses, closely supported by experienced dieticians and physicians. All patients treated with PEG are followed up by these specially trained nurses at the PEG outpatient clinic 2 weeks, 2 months and 6 months after the PEG insertion. The patient can contact the nurses by telephone or book additional appointments whenever needed.

\section{Statistical analysis}

For the purpose of this study all responses were dichotomized into "no" (response of "not at all" or "a little") versus "yes" (response of "quite a bit" or "very much"). Two of the questions had descriptive response alternatives and were presented separately. For comparisons of patient characteristics and clinical variables, Fisher's exact test was used to test for statistically significant differences at the 5 per cent level. Patients were stratified by sex, age (in two groups; $<65$ years and $\geq 65$ years), marital status (in two groups; married or cohabitant and single), level of education (in two groups; public/high school and university) and by diagnosis (in two groups; cancer and neurological disease).

\section{Ethics}

The patients and caregivers, or attending relatives, received oral and written information about the data collection and its use for research purposes, and the study was approved by the Regional Ethics Committee in Stockholm, Sweden.

\section{Results}

\section{Patients}

A total of 270 patients received a PEG during the study period. Within the 2-month follow-up period 51 patients died, 12 patients had the PEG removed, 3 patients were lost to follow-up and 55 patients were excluded according to the exclusion criteria without detailed information, leaving 149 patients eligible for the study. Among these, 147 patients (99\%) were followed up with an appointment at the outpatient clinic 2 months after PEG and $104(70 \%)$ responded to the questionnaire. Some characteristics of the study participants are presented in Table 1 . The majority were men (64\%) and the mean age 
Table 1 Characteristics of the 104 patients who had a percutaneous endoscopic gastrostomy (PEG) inserted and responded to a study specific questionnaire 2 months after PEG

\begin{tabular}{|c|c|c|}
\hline & Number & $\%$ \\
\hline \multicolumn{3}{|l|}{ Gender } \\
\hline Male & 67 & 64 \\
\hline Female & 37 & 36 \\
\hline \multicolumn{3}{|l|}{ Age $^{*}$} \\
\hline$<65$ years & 54 & 52 \\
\hline$\geq 65$ years & 50 & 48 \\
\hline \multicolumn{3}{|l|}{ Marital status } \\
\hline Married & 62 & 60 \\
\hline Single & 31 & 30 \\
\hline Missing & 11 & 11 \\
\hline \multicolumn{3}{|l|}{ Education } \\
\hline Public school/High school & 62 & 60 \\
\hline University & 31 & 30 \\
\hline Missing & 11 & 11 \\
\hline \multicolumn{3}{|l|}{ Diagnosis } \\
\hline Cancer & 78 & 75 \\
\hline Neurologic & 23 & 22 \\
\hline Other & 2 & 2 \\
\hline \multicolumn{3}{|l|}{ BMI } \\
\hline$<20$ & 29 & 28 \\
\hline$\geq 20$ & 71 & 68 \\
\hline Missing & 4 & 4 \\
\hline \multicolumn{3}{|l|}{ Enteral Nutrition via PEG } \\
\hline Daily & 84 & 81 \\
\hline More seldom & 10 & 10 \\
\hline Missing & 10 & 10 \\
\hline
\end{tabular}

was 64 years. Most patients were married $(60 \%)$ and had no university education (60\%). The indication for PEG was mainly due to a tumour $(75 \%)$ or neurological disorders $(23 \%)$, while only two patients were labeled "other causes" due to inflammatory diseases (myosit). More than a quarter of patients (28\%) were underweight with a body mass index (BMI) below 20. The majority of patients used their PEG daily (81\%) (Table 1). While about one third of the patients was not allowed to eat by mouth, the other patients could eat at least partly (Table 2).

\section{Differences in the experience of PEG}

Patients' perspectives of living with a PEG for at least two months are presented in Table 2. In Table 3 the responses have been dichotomized as described in the methods above. Women reported a more negative experience of living with a PEG compared to men, however only the feeling of limitation in daily activity reached the level of statistical significance $(p=0.004)$. Older patients reported similar experiences as younger patients except that older patients $(38 \%)$ experienced a more limited ability to influence the number of feeding times compared to younger patients $(19 \%)(\mathrm{p}=0.026)$. No statistically significant differences were found between married and single patients. More highly educated patients found feeding to be more time-consuming (55\%) than those with a public/high school education $(23 \%)(\mathrm{p}=0.004)$. Patients with a cancer diagnosis found that the PEG feeding interfered with their oral feeding statistically significantly more than patients with a neurological disease $(p=0.009)$. Nearly $20 \%$ of all patients reported that they were not satisfied with having a PEG. There were six patients that had never used their PEG for nutrition support (data not shown).

\section{Contact support and feeding assistance}

Table 4 presents patients' choice of contact whenever a problem regarding the PEG occurred. The majority of patients ( $\mathrm{n}=83$ including possible multiple responses) would turn to the PEG outpatient clinic with questions or problems regarding the PEG, followed by contact with the home care team $(n=15)$ and a dietician $(n=13)$. In Table 5, the results of patients' responses to the question about feeding assistance are presented. The majority of patients responded that they fed themselves $(n=63$ including possible multiple responses). The most common assistance was given by a spouse $(\mathrm{n}=18)$ or by personnel at the nursing home $(\mathrm{n}=10)$, and more seldom by district nurses $(\mathrm{n}=5)$.

\section{Discussion}

This exploratory study found that gender, age, education level and diagnosis are factors that might influence patients' experiences of living with a PEG, while marital status did not. This study also showed that patients preferred to contact the PEG outpatient clinic with problems about the PEG. Moreover, a majority of patients fed themselves with the PEG, but patients in need of assistance were mainly supported by their spouse and more seldom by district nurses.

Some methodological issues deserve attention. Our study period is limited to two months after the insertion of the PEG. A pre- and post period study should be interesting to paint a deeper light of the PEG experience. A threat to questionnaire surveys is selection bias due to non-participation or missing data. Although the response rate in the current study is relatively high (70\%) there is a risk of selection bias. Therefore, the results should be interpreted with caution. The data was collected during ongoing clinical care, and the time 
Table 2 Experience of living with a percutaneous endoscopic gastrostomy (PEG) among 104 patients who responded to a study-specific questionnaire 2 months after insertion

\begin{tabular}{lll}
\hline & Number & $\%$ \\
\hline Daily activity is limited due to the PEG & 50 & 48 \\
Not at all & 34 & 33 \\
A little & 14 & 13 \\
Quite a bit & 5 & 5 \\
Very much & 1 & 1 \\
Missing & & \\
Disturbed sleep & 61 & 59 \\
Not at all & 38 & 37 \\
A little & 3 & 3 \\
Quite a bit & 1 & 1 \\
Very much & 1 & 1 \\
Missing & & \\
PEG feeding is time consuming & 23 & 22 \\
Not at all & 39 & 38 \\
A little & 29 & 28 \\
Quite a bit & 7 & 7 \\
Very much & 6 & 6 \\
Missing & 6 &
\end{tabular}

Possibility to influence number of feeding times per day

\begin{tabular}{|c|c|c|}
\hline Not at all & 11 & 11 \\
\hline A little & 18 & 17 \\
\hline Quite a bit & 25 & 24 \\
\hline Very much & 48 & 46 \\
\hline Missing & 2 & 2 \\
\hline \multicolumn{3}{|c|}{ Confidence with self feeding } \\
\hline Not at all & 3 & 3 \\
\hline A little & 3 & 3 \\
\hline Quite a bit & 22 & 21 \\
\hline Very much & 39 & 38 \\
\hline Missing & 37 & 36 \\
\hline \multicolumn{3}{|c|}{ Interfere with your oral intake } \\
\hline Not at all & 38 & 37 \\
\hline A little & 15 & 14 \\
\hline Quite a bit & 4 & 4 \\
\hline Very much & 4 & 4 \\
\hline Nil per os & 31 & 30 \\
\hline Missing & 12 & 12 \\
\hline \multicolumn{3}{|c|}{ Satisfied with your PEG } \\
\hline Not at all & 9 & $y$ \\
\hline A little & 11 & 10 \\
\hline Quite a bit & 40 & 58 \\
\hline
\end{tabular}

Table 2 Experience of living with a percutaneous endoscopic gastrostomy (PEG) among 104 patients who responded to a study-specific questionnaire 2 months after insertion (Continued)

\begin{tabular}{lll}
\hline Very much & 36 & 35 \\
Missing & 8 & 8 \\
\hline
\end{tabular}

with each patient was limited. It is sometimes difficult to get elderly people and patients with neurological diseases to respond to questionnaires due to cognitive impairments [14]. However, patients not capable of self-responding to the questionnaire and those not familiar with the Swedish language were excluded from participation in this study. These might be patients who are more vulnerable and care-dependent, at least in this early post-treatment period [15]. There were only $23 \%$ of patients with neurological disorders included in this study material indicating that a majority of the neurological patients are excluded because of their state and impairment. The use of a structured self-report questionnaire restricts a deeper knowledge about patients experience, however, it is easy to respond to and not as time-consuming as the use of an interview approach.

Previous literature investigating the experience of living with a PEG is limited. The tradition in the older generations where the woman takes responsibility for the preparation of food [16] might explain the feeling of limited daily activity among women in the current study. Sociologically, different roles are taken by gender, with different ways of perceiving symptoms and the illness process, with a sometimes over-estimation of morbidity in women. In fact gender differences with consistently worse results among women have often been described in previous studies[17]. Our study confirms that the experience of living with a PEG was not affected by age except that the older patients experienced a decreased ability to influence the number of feeding times per day. Older patients may be more dependent on others than younger patients are [18] and this in turn might be a negative consequence of living with a PEG. Elderly patients with dependency on others seem to find it of great importance to be offered opportunities for living life as usual [19]. Patient satisfaction with care depends on the health problem for which the patient is being treated, but is generally high. Personal matters such as education level may however affect patients' perceptions of satisfaction with care. It has been concluded that satisfaction with care is higher in patients with a low level of education [20] which is in line with the results of the present study where patients with a university education found feeding to be more time-consuming than those with public or high school education. The fact that every 
Table 3 Experience of living with a percutaneous endoscopic gastrostomy (PEG) among 104 patients who responded to a study specific questionnaire 2 months after insertion in relation to personal characteristics

\begin{tabular}{|c|c|c|c|c|c|c|c|}
\hline & Gender & $p^{\#}$ & Age & $\mathrm{p}^{\#}$ Marital status $\mathrm{p}^{\#}$ & Education & $\mathrm{p}^{\#}$ & Diagnosis* \\
\hline Number (\%) & $\overline{\text { Number (\%) }}$ & & Number (\%) & Number (\%) & Number (\%) & & Number (\%) \\
\hline Tot & le & & $65 \geq 65$ & Married Single & $\begin{array}{l}\text { Public/high University } \\
\text { school }\end{array}$ & & ical \\
\hline
\end{tabular}

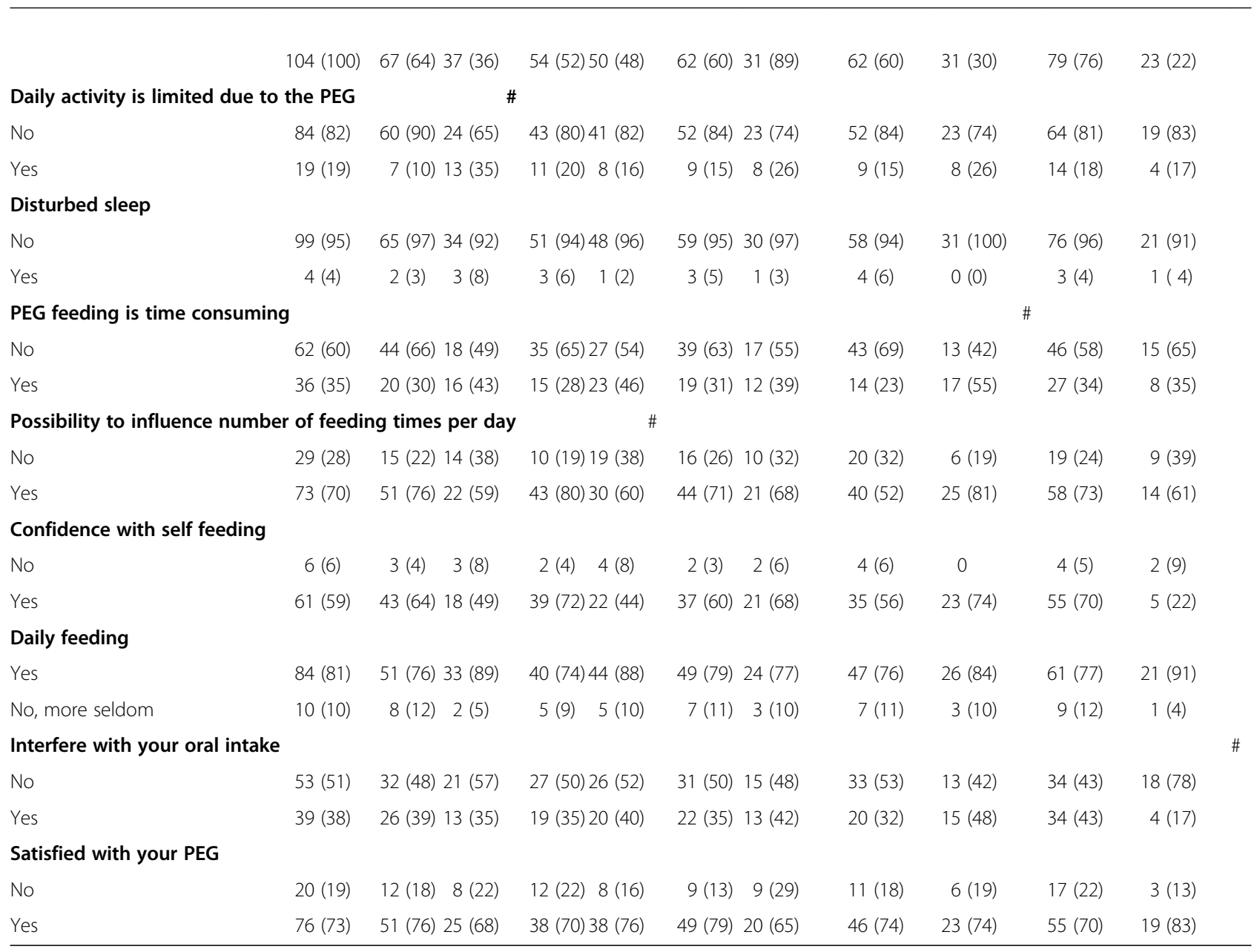

$\mathrm{No}=\mathrm{a}$ response of not at all or a little, Yes $=$ a response of quite a bit or very much. Due to missing answers, the number/frequencies of patients does not always add up to $104 / 100 \%$.

* There are two persons with other diagnoses that are not presented here, \# Statistical significance tested with Fisher's exact test. $p<0.05$.

fifth patient was dissatisfied with the PEG indicates a need for careful information about living with the PEG, before insertion of the PEG.

In order to maintain nutritional intake, PEG is often required for cancer patients during a restricted oncological treatment early in the care pathway, sometimes even before the need for enteral nutrition support, and for a limited period [21-23], while neurological patients most likely require a PEG later in the care pathway and will live with it for the rest of their lives. Once they agree to receive a PEG, they are perhaps more sympathetic to it. A PEG is suggested to be a milestone in the palliative care of ALS patients $[24,25]$ but the fact that $30 \%$ of the patients were underweight (BMI below 20) at the time of PEG in the current study might indicate the PEG insertion to be rather late in the care pathway for some patients. Clinical benefits for head and neck cancer patients are inconclusive [10]. Terrell et al. [26] found that the presence of a gastrostomy among head and neck cancer patients was associated with the statistically lowest scores in quality of life based on the SF-36 questionnaire, and suggest that gastrostomy is a constant reminder of the cancer disease during treatment. Cancer patients in the current study found the PEG feeding interfered with their oral intake to a larger extent than neurological patients did, but unfortunately there is not much written about these potential different experiences of living with a PEG when comparing 
Table 4 Contacts regarding questions or problems concerning the percutaneous endoscopic gastrostomy (PEG) among 104 patients who responded to a study specific questionnaire 2 months after insertion

\begin{tabular}{llll}
\hline Who do you contact with questions or problems concerning your PEG? & Total $(\mathbf{n = 1 0 4})$ & Male $(\mathbf{n = 6 7 )}$ & Number* \\
\cline { 2 - 4 } & & 56 & 27 \\
\hline PEG outpatient clinic & 83 & 8 & 7 \\
Home care team & 15 & 8 & 5 \\
Dietician & 13 & 6 & 3 \\
Primary care & 9 & 2 & 1 \\
Care staff at my nursing home & 3 & 1 & 1 \\
Other & 2 & 1 & 0 \\
Do not know & 1 &
\end{tabular}

*Patients can choose more than one answer.

diagnoses [27], but this is probably of great importance for health care professionals to keep in mind. Whatever the patients experience is of living with a PEG, enteral nutrition sometimes is the only alternative for sufficient nutrition.

The major PEG-related problems might not be discomfort, leakage or blockage, but rather interference with family life and social activities [12]. This might at least partly explain the experience of time-related problems described in this study. Previous research has reported that home care responsibility today is transferred to a larger extent to the patient and their relatives instead of primary care $[11,19]$. This is supported by the results from the current study that when needed, the patient was most often assisted by a spouse and more seldom by a district nurse. Since caring for PEG patients is time-consuming (up to 15 hours per week) [28] it may place a burden on family members by transferring the responsibility from primary care to the patient and their family [29].

It is important that the health care providers facilitate the insertion of PEG, increase the effectiveness of patient counseling and monitoring for complications and to inform and discuss the possibility to remove of the PEG

Table 5 Percutaneous endoscopic gastrostomy (PEG) feeding assistance among 104 patients who responded to a study specific questionnaire 2 months after insertion

\begin{tabular}{llll}
\hline Who help you with your PEG feeding? & $\begin{array}{l}\text { Total } \\
(\mathbf{n}=104)\end{array}$ & $\begin{array}{l}\text { Male } \\
(\mathbf{n}=67)\end{array}$ & $\begin{array}{l}\text { Female } \\
(\mathbf{n}=\mathbf{3 7})\end{array}$ \\
\cline { 2 - 4 } & \multicolumn{3}{c}{ Number* } \\
\hline Self care & 63 & 44 & 19 \\
Spouse & 18 & 11 & 7 \\
Care staff at my nursing home & 10 & 6 & 4 \\
District nurse & 5 & 3 & 2 \\
Home care team & 4 & 3 & 1 \\
Health care professionals at the hospital & 3 & 2 & 1 \\
Other relative & 2 & 2 & 0 \\
\hline
\end{tabular}

*Patients can choose more than one answer.
[30]. The finding that a large group of patients preferred to turn to the PEG outpatient clinic with questions or problems regarding the PEG and feeding, highlights this need for an outpatient clinic with specialized knowledge in PEG care, including a multidisciplinary team for referral of specific problems [31].

Previous research has shown that regular systematic nutrition team follow-up for gastrostomy-fed patients does not increase costs and may improve quality of care [8]. Therefore it can be recommended that all patients receiving a PEG should have access to an outpatient clinic with specialized knowledge in PEG care. There are several ways to improve the life of patients living with a PEG. Kurien et al. shows in a large prospective study that dietetic aftercare community service reduce hospital readmissions [32]. This is not surprisingly since Brotherton et al. found in semi-structured interviews with PEG patients that issues that was emergent related to the enteral feeding were disturbed sleep, limited ability to go out, limited choice of clothing, difficulties finding feeding places. [29] By contact with a dietician during the care pathway, support with enteral feeding can be arranged. Enteral formulas must not only suit the patient's specific nutritional needs, but might also suit the number of feedings per day and speed time for feeding. Moreover, the dietician can together with the patient and their relatives arrange the best suited device for the PEG feeding, as there is a range of devices for administration of enteral nutrition. For instance, mobile pumps and carrying packs with related giving sets can offer a more mobile life than drip stands do. At the time of discharge from hospital it is important that the health care professional at the hospital ward reports the patient to a district nurse. Health care professionals working in primary care are encouraged to collaborate and get support from the PEG outpatient clinic for the further care of the patient at home. This would make the district nurse feel more secure even if inexperienced in caring for problems regarding PEG and PEG feeding $[8,11,33]$. 


\section{Conclusion}

In conclusion, PEG is sometimes the only alternative to enable sufficient nutritional support but is timeconsuming and interferes with the daily life of the patient. Although a vast majority of patients are satisfied with their PEG, the experiences may be dependent on personal characteristics such as age, sex, education and the diagnosis. Family members are the main carers for PEG patients at home and if problems with the PEG arise, most patients turn to the PEG outpatient clinic for help.

\section{Competing interests}

The authors declare that they have no competing interests.

\section{Authors' contributions}

$L M, J B$ and $P L$ formulated the study hypothesis. $L M$ and $J B$ recruited the patients. LM and PL conducted the statistical analyses and LM, JB and PL interpreted the results. LM drafted the manuscript and JB and PL provided inputs. All authors read and approved the final version of the manuscript. PL provided funding.

\section{Financial support}

This study was supported by the Swedish Cancer Society and through the regional agreement on medical training and clinical research (ALF) between Stockholm County Council and Karolinska Institutet.

\section{Acknowledgements}

We express our gratitude to Margrete Gellervik for valuable administrative help, the nurses who cared for the patients with PEG and the management with all documentation, and to all staff involved at the endoscopy unit.

\section{Author details}

${ }^{1}$ Unit of Upper Gastrointestinal Research, Department of Molecular Medicine and Surgery, Karolinska Institutet, Norra Stationsgatan 67, 2nd floor, SE-171 76 Stockholm, Sweden. ${ }^{2}$ Department of Clinical Nutrition and Dietetics, Karolinska University Hospital, Stockholm, Sweden. ${ }^{3}$ Department of Surgical Gastroenterology, Karolinska University Hospital, Stockholm, Sweden.

Received: 3 May 2012 Accepted: 27 August 2012

Published: 18 September 2012

\section{References}

1. Scoping our practice:The 2004 report of National Confidential Enquiry into Patient Outcome and Death. http://www.ncepod.org.uk/2004report/index. htm.

2. Gauderer MW: Percutaneous endoscopic gastrostomy and the evolution of contemporary long-term enteral access. Clin Nutr 2002, 21(2):103-110.

3. Kurien M, McAlindon ME, Westaby D, Sanders DS: Percutaneous endoscopic gastrostomy (PEG) feeding. BMJ 2010, 340:c2414.

4. Bozzetti F, Braga M, Gianotti L, Gavazzi C, Mariani L: Postoperative enteral versus parenteral nutrition in malnourished patients with gastrointestinal cancer: a randomised multicentre trial. Lancet 2001, 358(9292):1487-1492.

5. Pirlich M, Schutz T, Norman K, Gastell S, Lubke HJ, Bischoff SC, Bolder U, Frieling T, Guldenzoph $\mathrm{H}$, Hahn $\mathrm{K}$, et al: The German hospital malnutrition study. Clin Nutr 2006, 25(4):563-572.

6. Braga M, Gianotti L, Nespoli L, Radaelli G, Di Carlo V: Nutritional approach in malnourished surgical patients: a prospective randomized study. Arch Surg 2002, 137(2):174-180.

7. Stratton RJ, Elia M: Who benefits from nutritional support: what is the evidence? Eur J Gastroenterol Hepatol 2007, 19(5):353-358.

8. Scott F, Beech R, Smedley F, Timmis L, Stokes E, Jones P, Roffe C, Bowling TE: Prospective, randomized, controlled, single-blind trial of the costs and consequences of systematic nutrition team follow-up over 12 mo after percutaneous endoscopic gastrostomy. Nutrition 2005, 21(11-12):1071-1077.
9. Katzberg HD, Benatar M: Enteral tube feeding for amyotrophic lateral sclerosis/motor neuron disease. Cochrane Database Syst Rev 2011, 19(1):CD004030.

10. Nugent B, Lewis S, O'Sullivan JM: Enteral feeding methods for nutritional management in patients with head and neck cancers being treated with radiotherapy and/or chemotherapy. Cochrane Database Syst Rev 2010, 17(3):CD007904.

11. Bjuresäter K: Home enteral tube feeding - from patients', relatives' and nurses' perspectives. Karlstad: Karlstad University; 2010.

12. Rogers SN, Thomson R, O'Toole P, Lowe D: Patients experience with longterm percutaneous endoscopic gastrostomy feeding following primary surgery for oral and oropharyngeal cancer. Oral Oncol 2007, 43(5):499-507.

13. Blomberg J, Lagergren P, Martin L, Mattsson F, Lagergren J: Novel approach to antibiotic prophylaxis in percutaneous endoscopic gastrostomy (PEG): randomised controlled trial. BMJ 2010, 341:c3115. doi:3110.1136/bmj.c3115

14. Bozzetti F: Quality of life and enteral nutrition. Curr Opin Clin Nutr Metab Care 2008, 11(5):661-665.

15. Carlsson E: Stroke and eating difficulties. long-term experiences 2004, 13(7):825.

16. Sidenvall B, Nydahl M, Fjellstrom C: The Meal as a Gift-The Meaning of Cooking Among Retired Women. J App/ Gerontol 2000, 19(4):405-423.

17. Orfila F, Ferrer M, Lamarca R, Tebe C, Domingo-Salvany A, Alonso J: Gender differences in health-related quality of life among the elderly: the role of objective functional capacity and chronic conditions. Soc Sci Med 2006, 63(9):2367-2380

18. Silver HJ, Wellman NS, Arnold DJ, Livingstone AS, Byers PM: Older adults receiving home enteral nutrition: enteral regimen, provider involvement, and health care outcomes. JPEN J Parenter Enteral Nutr 2004, 28(2):92-98.

19. From I, Johansson I, Athlin E: The meaning of good and bad care in the community care: older people's lived experiences. Int J Older People Nurs 2009, 4(3):156-165.

20. Findik UY, Unsar S, Sut N: Patient satisfaction with nursing care and its relationship with patient characteristics. Nurs Health Sci 2010, 12(2):162-169

21. Morton RP, Crowder VL, Mawdsley R, Ong E, Izzard M: Elective gastrostomy, nutritional status and quality of life in advanced head and neck cancer patients receiving chemoradiotherapy. ANZ J Surg 2009, 79(10):713-718.

22. Rutter CE, Yovino S, Taylor R, Wolf J, Cullen KJ, Ord R, Athas M, Zimrin A, Strome S, Suntharalingam M: Impact of early percutaneous endoscopic gastrostomy tube placement on nutritional status and hospitalization in patients with head and neck cancer receiving definitive chemoradiation therapy. Head Neck 2011, 33(10):1441-1447.

23. Talwar B, Findlay M: When is the optimal time for placing a gastrostomy in patients undergoing treatment for head and neck cancer? Curr Opin Support Palliat Care 2012, 6(1):41-53.

24. Silander E, Nyman J, Bove M, Johansson L, Larsson S, Hammerlid E: Impact of prophylactic percutaneous endoscopic gastrostomy on malnutrition and quality of life in patients with head and neck cancer - a randomized study. Head Neck 2011, 34(1):1-9.

25. Radunovic A, Mitsumoto $H$, Leigh PN: Clinical care of patients with amyotrophic lateral sclerosis. Lancet Neurol 2007, 6(10):913-925.

26. Terrell JE, Ronis DL, Fowler KE, Bradford CR, Chepeha DB, Prince ME, Teknos TN, Wolf GT, Duffy SA: Clinical predictors of quality of life in patients with head and neck cancer. Arch Otolaryngol Head Neck Surg 2004, 130(4):401-408.

27. Bannerman E, Pendlebury J, Phillips F, Ghosh S: A cross-sectional and longitudinal study of health-related quality of life after percutaneous gastrostomy. Eur J Gastroenterol Hepatol 2000, 12(10):1101-1109.

28. Verhoef MJ, Van Rosendaal GM: Patient outcomes related to percutaneous endoscopic gastrostomy placement. J Clin Gastroenterol 2001, 32(1):49-53.

29. Brotherton A, Abbott J, Aggett P: The impact of percutaneous endoscopic gastrostomy feeding upon daily life in adults. J Hum Nutr Diet 2006, 19(5):355-367.

30. Paramsothy S, Papadopoulos G, Mollison LC, Leong RW: Resumption of oral intake following percutaneous endoscopic gastrostomy. J Gastroenterol Hepatol 2009, 24(6):1098-1101.

31. National Collaborating Centre for Acute Care: Nutrition support in adults: Oral Nutrition Support, Enteral Tube Feeding and Parenteral Nutrition. London: National Institute for Health and Clinical Excellence; 2006:175. 
32. Kurien M, White S, Simpson G, Grant J, Sanders DS, McAlindon ME: Managing patients with gastrostomy tubes in the community: can a dedicated enteral feed dietetic service reduce hospital readmissions? Eur J Clin Nutr 2012, 66(6):757-760.

33. Mowe M, Bosaeus I, Rasmussen HH, Kondrup J, Unosson M, Rothenberg $\mathrm{E}_{\text {, }}$ Irtun O, Scandinavian Nutrition G: Insufficient nutritional knowledge among health care workers? Clin Nutr 2008, 27(2):196-202.

doi:10.1186/1471-230X-12-126

Cite this article as: Martin et al.: Patients' perspectives of living with a percutaneous endoscopic gastrostomy (PEG). BMC Gastroenterology 2012 12:126

\section{Submit your next manuscript to BioMed Central and take full advantage of:}

- Convenient online submission

- Thorough peer review

- No space constraints or color figure charges

- Immediate publication on acceptance

- Inclusion in PubMed, CAS, Scopus and Google Scholar

- Research which is freely available for redistribution 